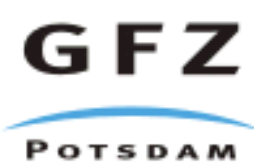

Originally published as:

Kotzé, P., Mandea, M., Korte, M. (2007): Modelling the southern African geomagnetic field secular variation using ground survey data for 2005. - South African Journal of Geology, 110, 2-3, 187-192,

DOI: 10.2113/gssajg.110.2-3.187. 


\title{
Modelling the southern African geomagnetic field secular variation using ground survey data for 2005
}

\author{
P. B. Kotzé \\ Hermanus Magnetic Observatory, Hermanus, South Africa (pkotze@hmo.ac.za) \\ M. Mandea and M. Korte \\ GeoForschungsZentrum, Potsdam, Germany (mioara@gfz-potsdam.de, monika@gfz- \\ potsdam.de)
}

(Final draft of paper: Kotzé, P., M. Mandea and M. Korte (2007): Modelling the southern African geomagnetic field secular variation using ground survey data for 2005. South African J. Geology, 110, 187-192.)

\begin{abstract}
It has been known that secular change is a comparatively local phenomenon and that it does not proceed in a regular way all over the Earth, giving rise to regions where the field changes more rapidly than elsewhere, like for instance southern Africa.

As part of a cooperative project between Germany and South Africa, called Inkaba ye Africa, the COMPASS (COmprehensive Magnetic Processes under the African Southern Sub-continent) program aims to study the geomagnetic field and in particular its evolutionary behaviour. In addition to a rapid decrease of the geomagnetic field in this region as evidenced by the $20 \%$ decrease observed at Hermanus, the orientation of the geomagnetic field in southern Africa is also changing rapidly. In the north-western part of southern Africa the declination of the magnetic field is propagating eastward (Tsumeb) and in the south-eastern part westward (Hermanus and Hartebeesthoek). This results in the spatial gradient over the subcontinent to increase with time. During 2005 a joint field survey campaign was conducted by the Hermanus Magnetic Observatory (HMO) and the GeoForschungsZentrum (GFZ) in southern Africa, including countries like South Africa, Namibia and Botswana in order to characterize the time variation of various components of the geomagnetic field. Results obtained from this field survey, together with information obtained from the previous field survey during 2004 at 8 field stations as well as the data from the 3 continuous recording magnetic observatories in southern Africa at Hermanus, Hartebeesthoek and Tsumeb, have been used to model the geomagnetic field time variation for 2004-2005, employing a polynomial approach.
\end{abstract}

\section{Introduction}

The geomagnetic field of the Earth varies on timescales ranging from seconds to millions of years. Variations on short timescales are mostly dominated by external sources, while variations on longer timescales ( $\sim 1$ year and longer) are collectively known as secular variation (SV) and are predominantly of internal origin. It is also known that secular change is a comparatively local phenomenon and does not proceed in a regular way all over the Earth [Bullard, 1948], giving rise to regions where the field changes more rapidly than elsewhere, as is the case for southern Africa. The observed high SV in 
southern Africa has been ascribed by Bloxham and Gubbins [1985] to rapidly drifting core spots. These intense patches normally occur in the Southern Hemisphere and drift westwards towards South America.

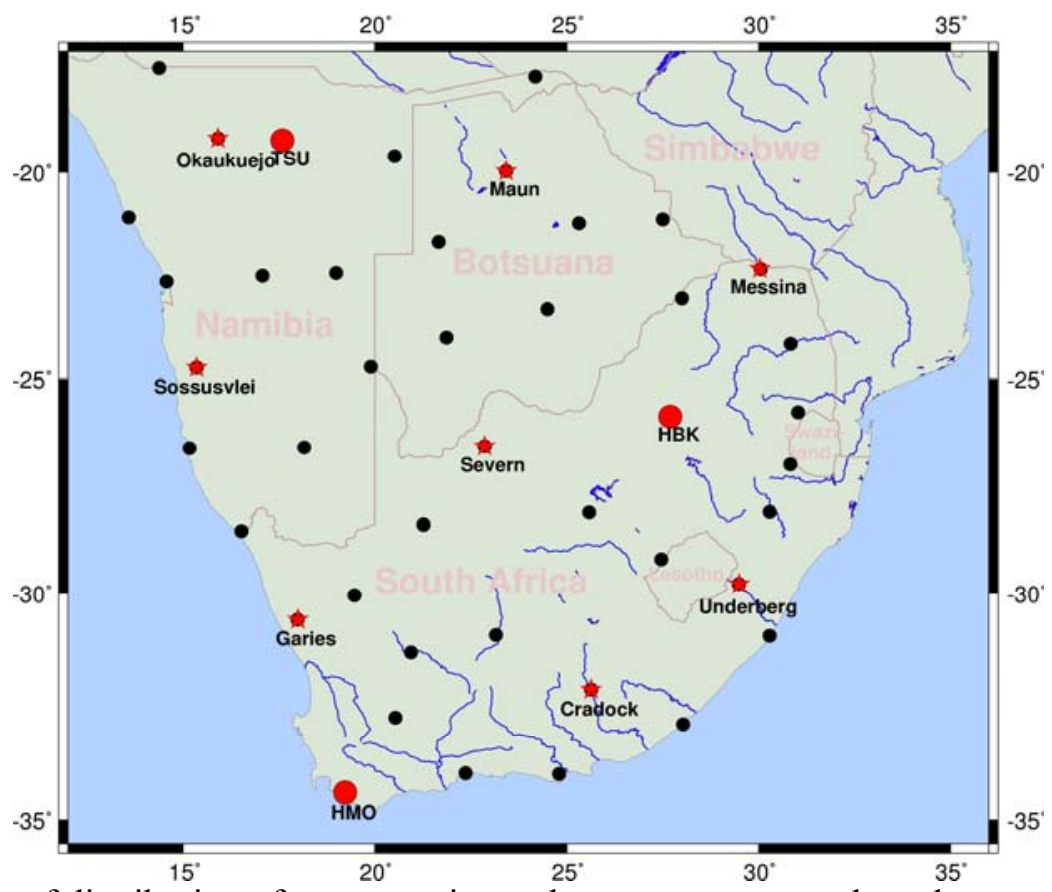

Figure 1. Map of distribution of repeat stations where measurements have been executed during 2004 and 2005 over the Southern African region. This map shows the positions of the 3 continuous recording magnetic observatories at Hermanus, Hartebeesthoek, and Tsumeb (indicated by $\bullet$ ), the field stations used for the derivation of secular variation information (indicated by *), as well as the complete set of stations (indicated by $\bullet$ ) visited during the 2005 campaign.

In order to better understand the mechanisms underlying the generation of the Earth's magnetic field, it is desirable to have as long a record as possible of the evolution of the field. The evolution of declination (the angle between the geographic and magnetic north directions) and inclination (the angle of the magnetic field with respect of the horizontal direction) of the magnetic field have been measured over many centuries (Alexandrescu et al., 1996, Mandea, 2000). In southern Africa, the Hermanus Magnetic Observatory (HMO) has been executing geomagnetic repeat surveys on a routine basis for close to 50 years. These surveys normally include countries such as South Africa, Namibia, Zimbabwe and Botswana and have been conducted at regular intervals of 5 years till 2000 at almost 70 positions. However due to the rapid change of the geomagnetic field in this region, it was decided to conduct field surveys on an annual basis, but at a few selected repeat stations. It was therefore decided to visit 8 selected repeat stations at annual intervals for 2003 and 2004. The experience gained from these surveys has shown that the limited number of stations over the Southern African region is insufficient to accurately model the secular variation due to the increasing temporal and spatial gradients. A better spatial resolution however demanded an increase in the density of the repeat stations. In 2005 a total of 40 stations were selected for a survey campaign. From 
the34 stations where it was possible to obtain good quality results, we selected only those where we made measurements in 2004 (Fig. 1).

These results were used to derive mathematical models of the time variation of all geomagnetic field components measured for the period 2004-2005, using polynomials that can be expressed as a function of latitude and longitude. In this publication we present modelling results for declination (D), horizontal component $(\mathrm{H})$, vertical component $(Z)$, as well as total field $(F)$.

\section{Data collection and field surveys}

Continuous recording of geomagnetic field variations are conducted at Hermanus $\left(34^{\circ}\right.$

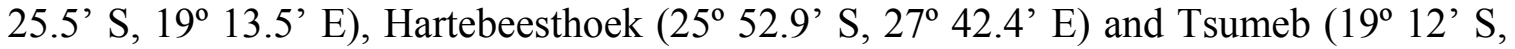
$\left.17^{\circ} 35^{\prime} \mathrm{E}\right)$. All these observatories comply with INTERMAGNET standards. The primary instrument for recording of magnetic field variations is the FGE fluxgate magnetometer, manufactured by the Danish Meteorological Institute in Copenhagen, Denmark. This instrument is based on three-axis linear-core fluxgate technology, optimised for longterm stability and records the components $\mathrm{H}, \mathrm{D}$ and $\mathrm{Z}$. An Overhauser-type magnetometer further provides absolute total field information, while baselines for the other components are obtained using a DI Flux theodolite.

For field survey purposes, field stations are marked by concrete beacons, ensuring that all observation points are exactly reoccupied during surveys. Most measurements are taken on a standard $1.2 \mathrm{~m}$ pillar, while in a few cases observers had to use a tripod mounted above a clearly marked shorter beacon. The field survey of 2005 was separated into three different sectors. At first a survey was done by only HMO field surveyors. Then 2 independent teams, each consisting of a staff member from HMO and GFZ, conducted a simultaneous field survey in southern Africa. A map showing the repeat station beacons visited in the present survey is shown in figure 1. At 8 stations the conditions were found to be not suitable for field survey measurements. Mostly it was a case that the region was no more magnetically quiet, or that the observation pillar was destroyed due to urban expansion projects. More information on the repeat station methodology are given by Korte et al. (2007, this edition) A DI fluxgate magnetometer was used as primary instrument during field surveys to obtain values of D and I, while an Overhauser magnetometer delivered values of total field intensity (F). Corrections for diurnal variation and other disturbing effects were made by comparing field station observations with magnetic data recorded on site with a LEMI suspended tri-axis fluxgate instrument. This proved to be a vast improvement by using magnetic observatories, sometimes a distance of more than $300 \mathrm{~km}$ away (see Korte et al, 2007, this edition).

\section{Modelling the Earth's magnetic field over the Southern African region}

Over the past few years since 2000, satellite data have been used extensively to model the main field, but not secular variation over southern Africa, especially to obtain information over areas not accessible by ground survey teams, like the surrounding ocean areas. Models derived in this way proved to be superior in resolution as well as accuracy to global field models when compared with ground observations (Kotzé, 2001). On the 
other hand however ground magnetic field measurements have been exclusively used to derive secular variation models for southern Africa (Kotzé, 2003). The field survey conducted in 2005 enabled polynomial-based secular variation models to be derived These models were $3^{\text {rd }}$ degree polynomials as a function of latitude and longitude, with 10 statistically significant coefficients for each magnetic field component modelled:
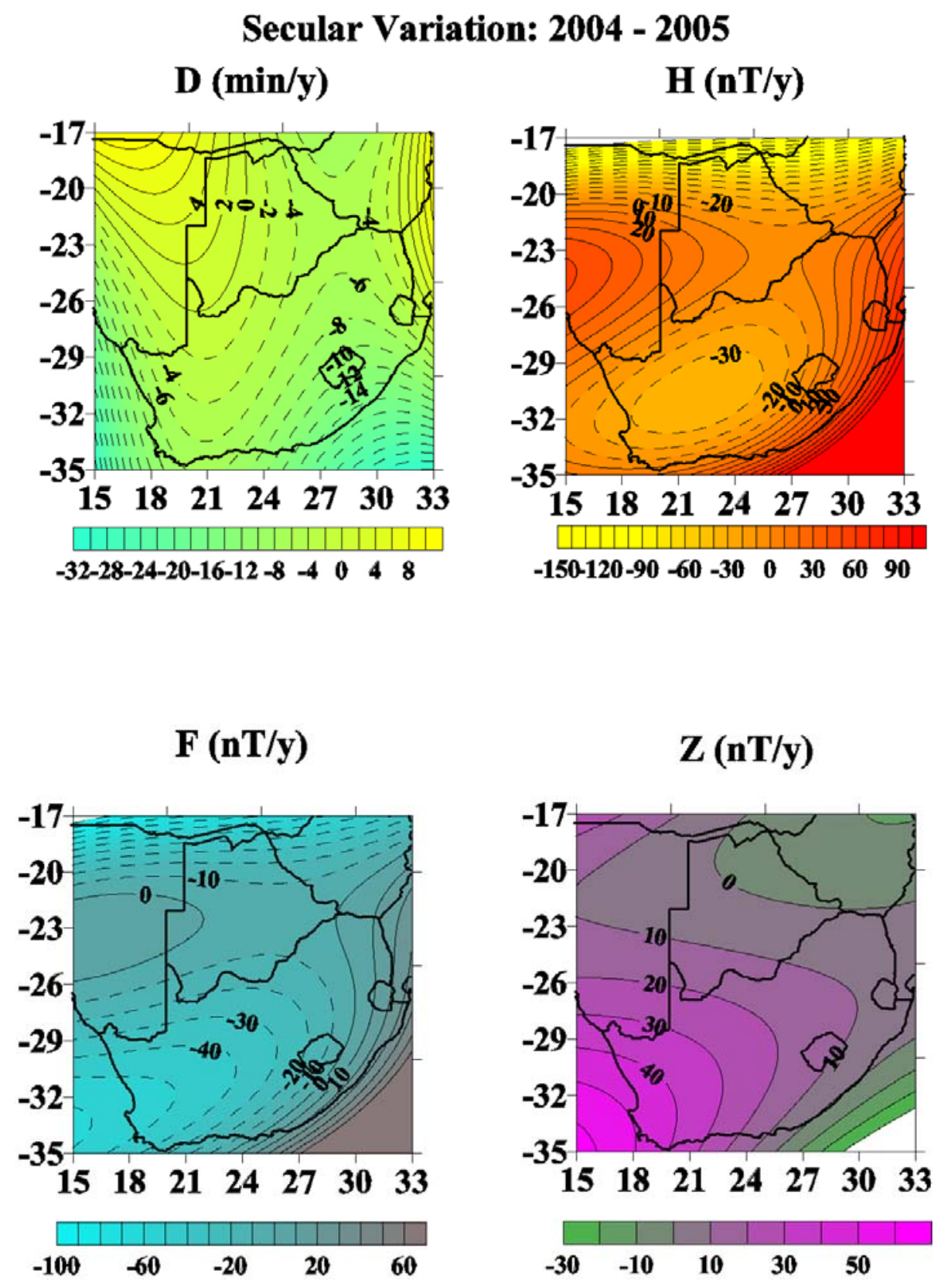

Figure 2. Contour plots showing the secular variation patterns over southern Africa for the different field components $\mathrm{D}, \mathrm{H}, \mathrm{Z}$, and $\mathrm{F}$, as determined by a $3^{\text {rd }}$ degree polynomial fit to field survey data of 2004-2005. 


$$
\begin{aligned}
& \mathrm{SV}=\mathrm{A}+\mathrm{BX}^{3}+\mathrm{CYX}^{2}+\mathrm{DXY}^{2}+\mathrm{EY}^{3}+\mathrm{FX}^{2}+\mathrm{GXY}+\mathrm{HY}^{2}+\mathrm{IX}+\mathrm{JY} \\
& \text { Where: } \\
& X=26^{\circ} \text { - Latitude } \\
& \mathrm{Y}=24^{\circ} \text { - Longitude } \\
& \mathrm{SV}=\text { Secular variation component }(\mathrm{F}, \mathrm{H}, \mathrm{D}, \mathrm{Z}) \\
& A-J=\text { coefficients derived from field survey data using least squares fit }
\end{aligned}
$$

Since secular variation is not measured directly, but is derived as a time derivative of the geomagnetic field, one can model the main field and then differentiate the corresponding field model to get a secular variation model, or one can numerically differentiate the main field data and then fit a secular variation model directly. The latter derivative-fit approach is able to remove crustal contamination and has been applied in this study of observatory and repeat station data. First central differences from annual mean observatory data as well as repeat stations, divided by their respective time intervals in years, were used as input data to our secular variation model. As observatory data, in general, are more accurate than repeat survey data, because of better baseline control and because seasonal and other short-term variations are more effectively removed by using annual means, we introduced weighing factors for both observatory and repeat station secular variation data in a ratio 1:0.7 in the least-squares solution. This ratio was determined by minimizing the RMS difference between model fits and survey data. There were 24 vector differences from 8 repeat stations and 9 vector differences from the 3 observatories, providing a total of 33 data values for the present time interval. A secular variation model for the period 2005.5 till 2007.0 was subsequently derived. The least-squares routine used to fit the data was the stepwise regression procedure described by Efroymson (1960), which has the ability of both entering and removing variables at given levels of statistical significance. The scatter about the fit for declination secular variation was less than $1 \mathrm{~min} / \mathrm{y}$.

Results obtained by modeling the field survey observations as obtained during the 2005 field survey of southern Africa can be seen in Figure 2. The IGRF 10 model was also compared with the observed secular variation pattern for 2004-2005 at all field stations, including the 3 magnetic observatories. The RMS differences between observations and models can be seen in Figure 3. Several interesting patterns are revealed for the secular variation observations in southern Africa, as discussed below.

\section{Conclusions}

Due to the rather dynamic variation of the magnetic field in the southern African region (see Mandea et.al, 2007, this edition), it is important that a dense array of suitable ground-based observations be employed.

Results obtained by modelling the declination secular variation for 2005 over southern Africa revealed a pattern dominated by an eastward variation in the north-western part of the region, while the south-eastern region of southern Africa is under the influence of a westward variation. This can clearly be seen in Figure 2. This indicates a growing gradient in the orientation of the geomagnetic field of southern Africa in a north-west, south-eastern direction. The pattern displayed by the horizontal component secular 
variation, also in Figure 2, clearly indicates that the sub-continent is divided into a central region where $\mathrm{H}$ is declining, as well as an north-western region with a growing tendency in $\mathrm{H}$. Therefore in the case of $\mathrm{H}$, like in declination, the growing gradient is in a northwest south-eastern direction, with a line of zero secular variation separating the 2 distinct regions. For the vertical field component, $Z$, the tendency is that of a diminishing field over the whole of southern Africa, as shown in figure 4. Over the south-western part of the subcontinent the decay in absolute values of $\mathrm{Z}$ is the most prominent. This is confirmed by the observed secular variation pattern for $\mathrm{F}$, also as displayed in figure 2 showing a large gradient in variation from east to west. In the south-western part of the sub-continent the total field is decreasing at a rate of more than $50 \mathrm{nT}$ per annum, whereas over the eastern part the field is almost constant.

\section{RMS Differences: Observations - Model}

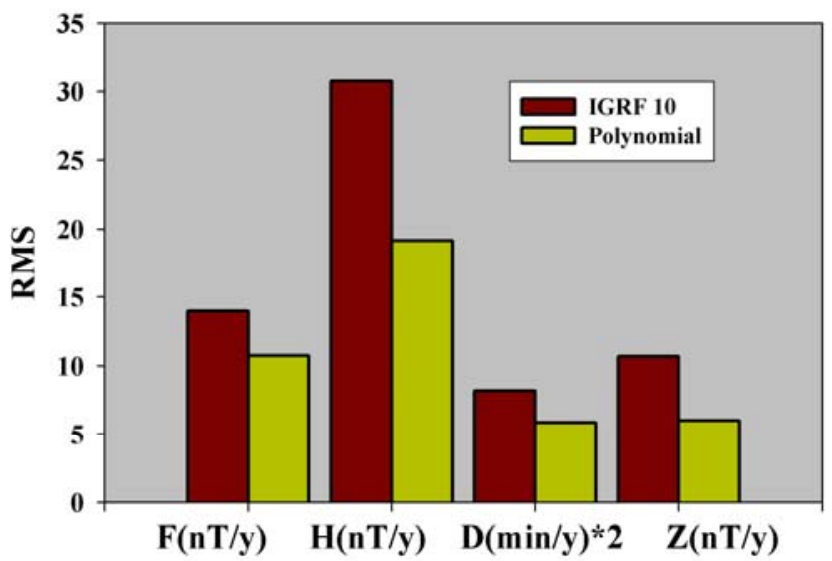

Figure 3. Root-mean square deviation of each model from observed rates of change in southern Africa during the period 2004-2005.

Figure 3 displays the root-mean-square deviations between the polynomial models as well as IGRF 10, and the data as obtained during the field surveys of 2004 and 2005. The general tendency shows that the regional field models are more accurate and representative of the southern African geomagnetic field secular variation. A statistical analysis between the polynomial-based models and IGRF 10, also reveals that the regional field models slightly underestimate the observed data, in contrast to IGRF 10 that overestimates observations.

Since the first magnetic field measurements started in the nineteenth century, a continuous decrease of the Earth's magnetic dipole moment has been observed. The change in the field strength is, however, not evenly distributed over the globe. In particular the most rapid decrease of the core field is observed in the Southern Atlantic region. In this regard southern Africa provides an ideal opportunity to study these geomagnetic field changes, as shown in the field survey done in 2005. Since the establishment of the Hermanus Magnetic Observatory in South Africa in 1941, the total field intensity has decreased by $20 \%$, which is greater than decreases observed at any other magnetic observatory. 
More interestingly, the growth and position changing of patches of the reverse flux under South African region, from 1840 onwards, can be responsible for changes in dipole moment. Moreover, it has been shown recently (Dormy and Mandea, 2005) that patches of intense secular variation appear in the South Atlantic hemisphere, with a very rapid displacement in a south-east - north-west direction, in line with observations of the present study. These measurements will have to be continued in future in order to track this patch and monitor its evolution with time. The last full southern African field survey was conducted in 2000, involving all 75 repeat station beacons. During 2005 some of these stations were visited for the first time since 2000. Results obtained during this field survey campaign showed that secular variation information, especially in southern Africa, must be obtained at regular short intervals, and that averaging over 5 years does not represent the true pattern for the time-varying geomagnetic field.

\section{Acknowledgements}

We wish to thank the Geological Survey of Namibia, Ministry of Mines and Energy, as well as the Geological Survey of Botswana for continuous support in carrying out repeat station measurements in these countries. We particularly acknowledge the active participation of Tiyapo Ngwisanyi in the 2005 survey in Botswana.

This work was made possible through financial support from the Hermanus Magnetic Observatory in South Africa as well as the GeoForschungsZentrum Potsdam, Germany. Support provided by the Geological Survey of Namibia in the operation of the magnetic observatory in Tsumeb is acknowledged.

\section{References :}

Alexandrescu, M., D. Gibert, D. Hulot, J-L. Le Mouël, and G. Saracco, Worldwide wavelet analysis of geomagnetic jerks, J. Geophys. Res., 101, 21975 - 21994, 1996.

Bloxham, J. and D. Gubbins, The secular variation of Earth's magnetic field, Nature, 317, 777-781, 1985.

Bullard, E. C., The secular change in the Earth's magnetic field, Mon. Notices Royal Astronom. Soc., Geophys. Suppl., 5, 248-257, 1948.

Dormy, E. and M. Mandea. Tracking geomagnetic impulses down to the core-mantle boundary, Earth Planet. Sci. Lett., 237, 300-309, 2005.

Efroymson, M.A., Multiple regression analysis, in Mathematical Methods for Digital Computers, edited by A. Ralston, and H.S. Wilf, pp 191-203, John Wiley, New York, 1960.

Korte, M., Mandea, M., Kotzé, P.B., Nahayo, E., and Pretorius, B., Implications of improved geomagnetic repeat station surveys of southern Africa for the Earth's conductivity, S.A. Journal of Geology, this edition, 2007. 
Kotzé, P.B., Spherical cap modelling of Ørsted magnetic field vectors over southern Africa, Earth Planets Space, 53, 357-361, 2001.

Kotzé, P.B., The time-varying geomagnetic field of Southern Africa, Earth Planets Space, 55, 111-116, 2003.

Mandea, M., French magnetic observation and the theory at the time of DE MAGNETE, Geomagnetism Research past and present, IAGA, Ed. W. Schroder, 73-80, BremenRoennebeck, 2000.

Mandea, M., M. Korte, and P. Kotzé, Magnetic field across southern African continent and its unique behaviour, S.A. Journal of Geology, this edition, 2007. 